Citation: B.W. Ninham, M. Shahid, R.M. Pashley (2020)AReview and Update of Bubble Column Evaporator Processes. Substantia 4(2) Suppl.: 19-32. doi: 10.36253/Substantia-823

Copyright: @2020 B.W. Ninham, M. Shahid, R.M. Pashley. This is an open access, peer-reviewed article published by Firenze University Press (http://www.fupress.com/substantia) and distributed under the terms of the Creative Commons Attribution License, which permits unrestricted use, distribution, and reproduction in any medium, provided the original author and source are credited.

Data Availability Statement: All relevant data are within the paper and its Supporting Information files.

Competing Interests: The Author(s) declare(s) no conflict of interest.

\section{A Review and Update of Bubble Column Evaporator Processes}

\author{
Barry W. Ninham ${ }^{1}$, Muhammad Shahid ${ }^{2}$, Richard M. Pashley ${ }^{2, *}$ \\ ${ }^{1}$ Department of Applied Mathematics, Research School of Physical Sciences, The Austral- \\ ian National University, Canberra, Australia \\ ${ }^{2}$ School of Science, University of New South Wales, Northcott Drive, Campbell, Canberra, \\ Australia \\ ${ }^{*}$ Corresponding author: r.pashley@adfa.edu.au
}

\begin{abstract}
This paper gives an updated review of the bubble column evaporator (BCE) and its various new processes. These include recent work on helium gas desalination and high temperature inlet gas decomposition. The BCE process offers a continuously produced source of high gas-water interface and consequently provides high overall heat and mass transfer coefficients. Very different results have been obtained using nitrogen, oxygen, carbon dioxide and helium inlet gases. Although the bubbling process itself is both simple to use and apply, our understanding of the fundamental physical and chemical principles involved is surprisingly limited and there are many issues yet to be explained. Recently the process has been used to develop new methods for the precise determination of enthalpies of vaporisation $\left(\Delta H_{\text {vap }}\right)$ of concentrated salt solutions, as an evaporative cooling system, a sub-boiling thermal desalination unit, for sub-boiling thermal sterilization, for low temperature thermal decomposition of different solutes in aqueous solution and for the inhibition of particle precipitation in supersaturated solutions. These novel applications can be very useful in many industrial practices, such as desalination, water/wastewater treatment, thermolysis of ammonium bicarbonate $\left(\mathrm{NH}_{4} \mathrm{HCO}_{3}\right)$ for the regeneration in forward osmosis and refrigeration related industries. The background theories and models use to explain the BCE process are also reviewed and this fundamental knowledge is applied to the design of BCE systems and to explain recently explored applications, as well as potential improvements. Many other prospective applications of the BCE process are also reported in this paper.
\end{abstract}

Keywords: bubble column evaporator, sub-boiling, bubble inhibition, thermolysis, desalination, heat of vaporisation, supersaturation.

\section{INTRODUCTION TO THE BUBBLE COLUMN EVAPORATOR (BCE)}

Double, double toil and trouble; Fire burn: and, cauldron, bubble. The three witches of Shakespeare's play McBeth: Act 1V, Scene 1 (1606) seem to be the first to have used hot bubble columns effectively. However, the witches use of various outrageous potions distilled from animals would be forbidden in our present politically correct society. Nonetheless bubble column evapo- 
rators or BCEs are simple devices that have emerged as facilitators of powerful new technologies for aqueous systems in:

- Desalination (seawater and groundwater).

- Water sterilization (recycled water with no surviving pathogens including viruses).

- Thermolysis of solutes in aqueous solution (destruction of drugs, facilitation of high temperature reactions).

- Inhibition of salt precipitation in concentrated salt solutions.

- Evaporative air conditioning systems for buildings.

The first three are now proven processes, and cheap at industrial scales. They represent encouraging progress in the search for clean water, arguably the biggest problem facing the world.

\section{BUBBLE COLUMN EVAPORATORS AS CONVENTIONAL EQUIPMENT}

By itself the bubble column evaporator (BCE) is a good and faithful and apparently boring tool of Chemical Engineering. It employs gas-liquid interfaces to drive fundamental processes involving heat and mass transfer. Bubble columns are devices in which a gas, often dry air, is pumped through a porous sinter disc to form gas bubbles in contact with the column solution. They are continuously replenished. Dry gas bubbles in the column solution may be used simply to mix the liquid phase homogenously to attain uniform temperature distribution or to saturate dissolved gases in the column solution. Substances can also be transferred from one phase to the other, for example, when liquid reaction products are stripped from a gas, where both mass and heat transfer processes can occur simultaneously.

Heat transfer using shell and tube heat exchangers is a fundamental chemical engineering process by which heat is transported between two fluids via a material having high thermal conductivity (i.e. copper, $\mathrm{Cu}$ ). Heat transfer may also be accomplished directly by mixing the solution and the heating fluid (for example, water and hot air bubbles), to give so-called direct-contact evaporators. This concept of heat transfer via hot bubbles was first demonstrated by Collier in a patent, published in $1887 .^{2}$ The first commercial plant was installed in the USA in the early $20^{\text {th }}$ century. ${ }^{3}$ There has been much attention on the industrial uses of bubbles columns in the chemicals industry, including a volume in Chemical Engineering Technology in 2017. ${ }^{4}$ Much work has also been carried out on the difficult area of numerical modelling of turbulent bubble column reactors. ${ }^{5}$
Advantages of bubble columns, using direct-contact heat transfer, compared to other multiphase reactors are several: (a) less maintenance required due to the absence of moving parts, (b) higher effective interfacial areas and overall mass transfer coefficients can be achieved, (c) higher heat transfer rates per unit volume of the reactors can be attained, (d) solids can be handled without any erosion or plugging problems, (e) less floor space is occupied and bubble column reactors are less costly, (f) slow reactions can be carried out due to high liquid residence time, ${ }^{6}$ and $(\mathrm{g})$ the product can be recovered from the reaction mixture without additional separation operations. ${ }^{1}$ Finally, and a glaringly obvious technology still to be exploited, high temperature reactions can be carried out at the surface of bubbles whilst maintaining a relatively low temperature in the liquid column.

\section{EXTRAORDINARY SALT INDUCED BUBBLE FUSION INHIBITION}

\subsection{New Opportunities for the BCE}

The BCE is easy to use. But a theoretical understanding of processes involved is still embryonic. It becomes more difficult to understand when a new phenomenon is thrown into the mix. This is the phenomenon of bubble coalescence inhibition with addition of salt. This was first used experimentally by Russian mineral coal flotation engineers more than 100 years ago. The addition of sufficient salt inhibits bubble-bubble fusion, produces smaller bubbles, and the efficiency of flotation was improved. ${ }^{7}$ More recently, aqueous bubble column evaporators have been used for a range of new applications based largely on the unexpected effects of many salts and sugars on inhibiting bubble-bubble coalescence in water, in combination with limited bubble rise rates and rapid water vapour uptake into the bubbles. ${ }^{8-13}$

The percentage of bubbles that fuse as a function of salt concentration as they ascend the column and the transition from $100 \%$ fusion on collision to zero fusion occurs over a narrow concentration range centered at the same $0.175 \mathrm{M}$ for 1:1 salts. Similarly for others like 2:1, 1:2, 3:1, 3:2 electrolytes and so on but at different concentrations. However, for other salts no such effect occurs. ${ }^{11,14-15}$ There are a set of rules that assign each ion pair to either class, and that allow prediction for outcomes with mixtures. ${ }^{11,14}$ There are no exceptions. The phenomenon occurs also for different isomers of sugars and other solutes. ${ }^{11}$ There is no theoretical explanation. ${ }^{14-15}$ Classical theories of molecular forces (e.g. DLVO forces) would predict that increased salt ought to 
reduce double layer forces between bubbles and enhance, not inhibit bubble fusion. With non-ionic solutes no electrostatic theory is relevant anyway.

Even more remarkable is that the fact that the ionic strength of blood is exactly the same critical concentration. There are good physiological reasons for this has recently been discovered. ${ }^{16}$ It is also the same concentration as that estimated for the Permian ocean when land animals emerged.

The absence of any theoretical explanation for the bubble coalescence phenomenon has not inhibited the development of a wide range of useful techniques. These include:

- A new method for the precise determination of enthalpies of vaporisation $\left(\Delta H_{\text {vap }}\right)$ of concentrated salt solutions; ${ }^{10,15}$

- Evaporative cooling; ${ }^{10}$

- A new method for thermal desalination; $;^{17-19}$

- A novel method for sub-boiling, thermal sterilization; ${ }^{20-22}$

- A novel method for the low temperature thermal decomposition of different solutes in aqueous solution $^{8}$ and

- A new approach to aqueous precipitation in a controlled manner ${ }^{23}$ (see Fig. 1).

In addition to these methods, the thermal design of a bubble column condenser has also been studied for the production of high quality water as condensate. ${ }^{24-26}$
Bubble coalescence behaviour is vital in water-based cleaning processes, ore-flotation, food processing, gasoil separations, absorption and distillation. ${ }^{27}$ As discussed above, bubble coalescence inhibition depends critically on salt type as well as concentration. ${ }^{11,28}$ Salt solutions that do inhibit coalescence have recently been used in many applications, as illustrated in Fig. 1.

All attempts to explain the inhibition problem and its salt dependence with theory have failed. That is not surprising as the theories of forces in colloid science suffer from sins of omission and commission that are now as well documented as they are ignored.

These are:

1. The ansatz of separability of electrostatic and dispersion forces. This violates two fundamental laws of thermodynamcs, even in the continuum solvent model, and dismisses specific ion effects.

2. Hydrophobic interactions are ill defined and depend on dissolved gas. ${ }^{29}$

We can speculate that the theories fail because of the omission, not just of dissolved gas, but of the capacity of dissolved gas to self assemble into dynamic microstructures, just as do surfactants. Nanobubbles seem to have critical nanobubble concentration $\mathrm{CNC}$, which is salt and salt concentration dependent, just as do the CMCs of surfactants. Such nanobubbles would inhibit fusion by depletion forces and adsorption at the mac-

\section{Desalination}

Evaporative Cooling

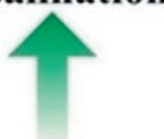

Thermal

\section{Sterilization}

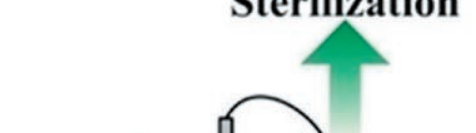

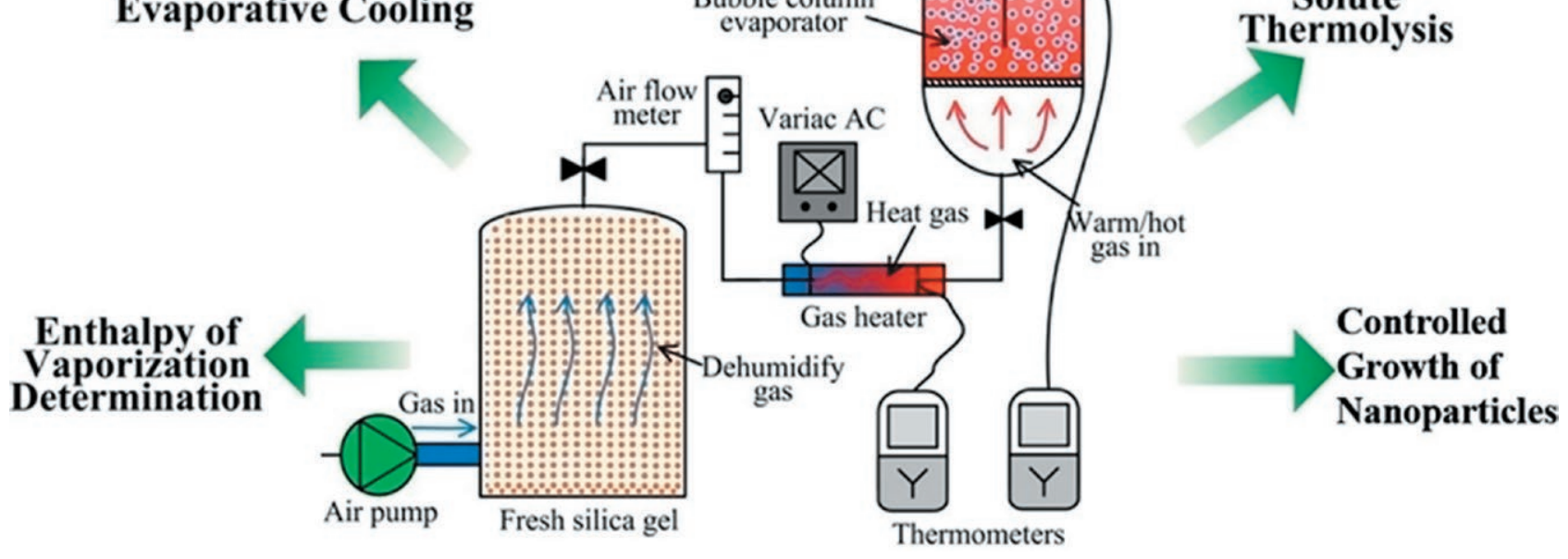

Figure 1. Different applications of the BCE process (reprinted by permission of the publisher, Taylor\&Francis Ltd, http://www.tandfonline. com, from M. Shahid et al. 2015). ${ }^{8}$ 
robubble surfaces. For a history of nanobubbles see Ref 30. The bubble coalescence process is not obvious partly because it is also dependent on dynamic effects, since bubbles slowly forced together always coalesce in aqueous salt solution.

\subsection{Bubble evaporation layer model}

The deficiencies of the classical theories of forces does not inhibit us from applying thermodynamics to explore some important aspects of bubble column evaporators. The bubble evaporation layer model presented here is based on the estimated thickness of a heated water layer formed transiently around the surface of an initially dry, hot bubble. Some of this water layer must be evaporated into the bubble to produce saturated vapour pressure, at that temperature. This surface bubble layer thickness is a function of temperature and bubble diameter. It will be useful in considering heat and mass transfer processes for desalination, sterilization and other applications. The bubble layer thickness $\left(t_{\mathrm{bl}}\right)$ varies with temperature, and this model can be described by the following equation for situations where the evaporated film thickness is much less than the radius of the bubble:

$t_{\mathrm{bl}}=\frac{1}{3} r \frac{\rho_{\mathrm{W}}^{v}\left(T_{\mathrm{c}}\right)}{\rho_{\mathrm{w}}}$

where $r$ is the radius of a bubble; $\rho_{\mathrm{w}}^{v}\left(T_{\mathrm{c}}\right)$ is the water vapour density at the steady state column temperature and $\rho_{w}$ is the liquid water density. Eq. (1) shows that the bubble layer thickness is a function of steady state column temperature. As an example, for water the average evaporation layer thickness would be about $23 \mathrm{~nm}$ for an inlet dry air temperature of $200{ }^{\circ} \mathrm{C}$, forming $1 \mathrm{~mm}$ radius bubbles.

\subsection{Bubble surface hot layer model}

Water vapor is transported through the surface of a hot, dry bubble as it enters a BCE. Simultaneously heat will also flow to a thin water layer surrounding the bubble, as the bubble approaches steady state and cools to the temperature of the column solution. A transient hot water film will be produced around the bubbles flowing into a $\mathrm{BCE}$ and this layer can be used to effect changes within the solution. It is therefore useful to consider the likely thickness of this heated layer as a function of inlet air temperature. These thermal effects appear to play a key role for heat transfer processes like sterilization ${ }^{20-22}$ and solute thermal decomposition. ${ }^{8}$ The maximum extent of the layer can be estimated for a given inlet air temperature. The estimate assumes that there is a linear decrease in the temperature of the surrounding water film from the bubble temperature to the column solution temperature. The thermal energy supplied to heat the water film must be supplied by cooling of the freshly released bubble. (Note that the millimetre bubble surface can be considered to be flat relative to the thin, nanometre thickness of the heated water layer).

In this simple model we consider the intermediate state when the inlet bubble (initially at a high temperature $T_{\mathrm{i}}$ ) has cooled from $T_{\mathrm{i}}$ to $T_{\mathrm{b}}$ (assumed to be 100 ${ }^{\circ} \mathrm{C}$ ) and the heat transferred to the thin water film surrounding the bubble is sufficient to produce this temperature profile in the film. This amount of heat is the same as that required to heat a film of thickness $\delta$ from the column solution temperature $T_{\mathrm{c}}$ to the average film temperature $\left(T_{\mathrm{b}}+T_{\mathrm{c}}\right) / 2$. The bubble layer thickness varies with bubble radius, the temperature of the inlet gas and the steady state column solution temperature. A rough estimate of the heated layer thickness can be calculated using the thermal energy balance equation: ${ }^{8,20}$

$C_{p} \Delta \operatorname{Tr}=3 C_{s} \Delta t \delta$

where $C_{\mathrm{p}}$ and $C_{\mathrm{s}}$ are the air and solution (or water) specific heat capacities in $\mathrm{J} / \mathrm{m}^{3} \mathrm{~K}$, respectively, and $\Delta t=\frac{T_{b}+T_{c}}{2}-$ $T_{c}$ and $\Delta T=T_{i}-T_{b}$ are the transient temperature increase in the solution layer and the temperature reduction within the cooling bubbles, respectively. (Note that in this approximate equation the value of $C_{p}$ should be taken as that at the average temperature of the cooling bubbles, i.e. at $T=\left(T_{i}+T_{b}\right) / 2$ and the value of $C_{s}$ should be that at $\left.T=\left(T_{b}+T_{c}\right) / 2\right)$.

The volume of a layer of thickness $\delta$ around a bubble is given by $4 \pi r^{2} \delta$, when $\delta$ is much smaller than $\mathrm{r}$. Hence the cooling of the bubble by $\Delta T$ must determine the thickness $\delta$. In addition, if we also assume that there is a $50 \%$ heat loss due to water vaporisation, then the thickness of the active hot region can be roughly estimated. For example, this approximate calculation indicates that for $1 \mathrm{~mm}$ radius (dry) air bubbles, at an inlet temperature of about $200{ }^{\circ} \mathrm{C}$, on cooling to $100{ }^{\circ} \mathrm{C}$, forms a transient heated water film around the rising bubbles of about 50 nm thickness.

This transient layer of heated water around the bubbles must be responsible for the sterilization effects ${ }^{20-22}$ and solute thermal decomposition effects ${ }^{8}$ recently reported when using inert gases, such as nitrogen. However, in addition to these thermal effects some gases also have specific properties which can also produce effects 
on solutes and microorganisms in bubble columns. For example, recent results have shown that $\mathrm{CO}_{2}$ inlet gas can be more effective at virus and bacterial sterilization and can even be effective at low temperatures. ${ }^{34}$ The use of hot, pure $\mathrm{O}_{2}$ inlet gas can also be used to enhance solute oxidation processes, whilst maintaining a relatively low BCE solution temperature.

\subsection{Bubble water vapour equilibration}

It has been observed that fairly large air bubbles (1-3 mm) in water, which are used in the BCE method, become non-spherical and oscillate both in shape and trajectory, thus enhancing the rate at which water vapour equilibrates within the bubbles. ${ }^{35}$ It is remarkable that water vapour saturation within these bubbles is attained in a few tenths of a second. It does so because of these oscillations and the circulatory fluid flow induced inside the bubbles due to shear forces generated at the surface of bubbles. This produces rapid water vapour transfer within the bubbles. ${ }^{36}$ The vapour transfer is much faster that that expected for quiescent diffusion, which would require several seconds to reach equilibrium according to Fick's law. This rapid vapour transfer must correspond to a similarly fast rate of transfer of heat to the surrounding column solution. It is these factors that form the basis for several recent applications (see Fig. 1) of the BCE process.

\subsection{Bubble rise velocity}

Bubble rise behaviour in water, even for single isolated air bubbles, is surprisingly complex ${ }^{35,36}$ and depends on bubble diameter, sphericity and water purity. ${ }^{37}$ The presence of many other bubbles within a BCE makes this situation even more complex and this has not been well studied. The rise of a bubble in a liquid is a function of many parameters viz. bubble characteristics (diameter and shape), properties of gas-liquid systems, and operating conditions, temperature, cleanliness etc.

It was demonstrated by Leifer et al. ${ }^{35}$ that the motion of intermediate (single, isolated) bubbles ranging from 1-3 mm diameter is produced by the combination of two oscillation types, trajectory oscillations (zig-zag or helical), and shape or deformation oscillations (ellipsoidal). These gas bubbles actually rise at a limited rate of between about 15 and $35 \mathrm{~cm} \mathrm{~s}^{-1}$ in quiescent water because they undergo trajectory and shape oscillations which reduce their rise rate. ${ }^{38}$

Quinn et al. ${ }^{39}$ reported that the shape and velocity of ellipsoidal bubbles appears to oscillate in a fashion linked with increasing solute concentration. Increased solute concentration creates more spherical bubbles with reduced rise velocity and a unique bubble shape. The rise velocity relationship is independent of solute type.

It was also explained by Gonzaleztello et al. ${ }^{40}$ that surfactants modify the surface of a bubble predominately through the adsorption of a monolayer. This produces a more rigid interface and so enhances fluid drag. The rise velocity in these solutions is less than for clean bubbles of the same diameter.

Luo et $a .^{41}$ have studied the rise velocity of single bubbles in liquid-solid suspensions at pressures up to $17 \mathrm{MPa}$ and temperatures up to $88^{\circ} \mathrm{C}$, over the bubble diameter range from 1 to $20 \mathrm{~mm}$. It was found that the bubble rise velocity decreased with increasing pressure and with decreasing temperature. The decrease of bubble rise velocity was mainly due to the variations of gas density and liquid viscosity with pressure and temperature.

Many researchers have described several factors affecting bubble rise velocity. ${ }^{37}$ But the detailed understanding of bubble rise velocity and its associated parameters with regards to the bubble column evaporator method (BCE) is yet to be thoroughly explained.

Stokes' law was derived for spherical objects moving under high Reynolds number and with zero slip boundary condition and gives rise rates substantially higher than those observed for air bubbles in water. Unfortunately, the addition of slip boundary conditions would give even higher rise rates, such as those obtained using the Hadamard-Rybczynski $(\mathrm{H}-\mathrm{R})^{42}$ equation (see Fig. 2 (a)). The Levich ${ }^{43}$ formula gives results more closely resembling experimental rates and this is also given in Fig. 2. Eq (3) represents the general formula for the theoretical bubble rise calculation but unfortunately, none of these equations give an accurate explanation of air bubbles in the $1-3 \mathrm{~mm}$ diameter range of interest. ${ }^{35,44}$ The general formula is given by the equation:

$U_{\infty}=k \frac{\rho_{\mathrm{w}} g a^{2}}{\eta}$

where $U_{\infty}$ is the bubble rise velocity in an infinite liquid, $\eta$ is the coefficient of viscosity of the liquid, $\rho_{\mathrm{w}}$ is the density of the liquid, $g$ is the gravitational constant, $a$ is the gas bubble radius and $k$ is a constant (2/9 for Stokes equation, $1 / 3$ for the Hadamard-Rybczynski equation and $1 / 9$ for the Levich equation) (see Fig. 2 (a)). The three typical equations, discussed earlier, have closer agreement with the experimental results summarised by Klaseboer et al. in Fig. 2 (b) ${ }^{45}$ when bubble diameters are less than about $1.0 \mathrm{~mm}$. 

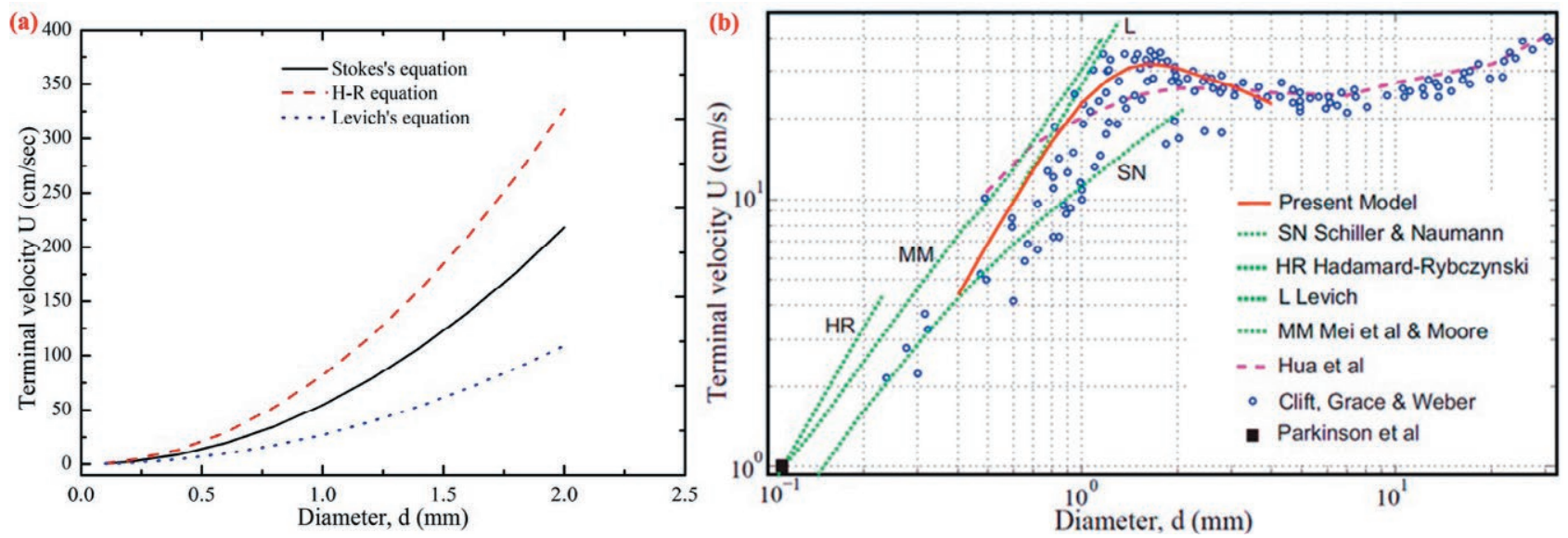

Figure 2. The relationship between rise velocity of isolated bubbles and bubble diameter using typical equations (a) and from models results (b) published by Klaseboer E. et al. ${ }^{45}$ (Reprinted from Ref. 45, with permission from Elsevier).

The complex behaviour of bubble rise rates for isolated bubbles in the diameter range $>1 \mathrm{~mm}$ will be further complicated by multiple collisions within a densely packed bubble column, where coalescence is inhibited by the presence of added salts.

\subsection{Thermal energy balance in the $B C E$}

Consideration of the steady state thermal energy balance within a BCE, containing salt solutions can be used to explain the process whereby the heat supplied from the entering warm bubbles (per unit volume of gas leaving the column) is balanced by the heat required for vaporisation, to reach the equilibrium water vapour pressure within these bubbles. This principle is based on the steady state volumetric balance within a bubble column, which has been used for the determination of the enthalpy of vaporisation $\left(\Delta H_{\text {vap }}\right)$ of concentrated salt solutions, ${ }^{9-10,18}$ and is described by the following Eq. (4):

$$
\Delta T \times C_{p}\left(T_{e}\right)+\Delta P=\rho_{v}\left(T_{e}\right) \times \Delta H_{v a p}\left(T_{e}\right)
$$

where $C_{p}\left(T_{\mathrm{e}}\right)$ is the specific heat per unit volume of the gas flowing into the bubble column at constant pressure; $T_{\mathrm{e}}$ is the steady state temperature near the top of the column; $\rho_{v}$ is the water vapour density at $T_{\mathrm{e}}$, which can be calculated from the water vapour pressure of salt solutions at the steady state temperature, using the ideal gas equation; $\Delta T$ is the temperature difference between the gas entering and leaving the column; $\Delta P$ is the hydrostatic differential pressure, between the gas inlet into the sinter and atmospheric pressure at the top of the column. This represents the work done by the gas flowing into the base of the column until it is released from the solution.
This equation was first published in 2009 by Francis and Pashley ${ }^{10}$ for low vapour pressure aqueous solutions, that is, at low column temperatures of about 283 $\mathrm{K}$. The equation's accuracy and precision was further tested in later studies ${ }^{9,18}$ at room temperature. The units used throughout the equation are $\mathrm{Jm}^{-3}$, which relates directly to the thermal energy transfer or work done per unit volume of gas flow passing through the column, at the steady state temperature of the column. Once the steady state is reached, then assuming no heat losses to the environment, the cooling of each bubble entering the column exactly balances, on average, the latent heat required to vaporize water to reach the equilibrium vapour pressure with that bubble, at that steady state temperature. This thermal energy and work done per unit volume of gas, means that once the steady state temperature is reached, the balance given in equation (4) is independent of gas flow-rate. However, the time taken to reach the steady state temperature will depend on the gas flow rate.

In a more recent variation of this energy balance equation, use of the heat capacity per unit volume, $C_{p}$, in volume-based units was replaced by the corresponding heat capacity per unit weight of gas (i.e. $1.005 \mathrm{~J} \mathrm{~g}^{-1}$ $\mathrm{K}^{-1}$ over $270-330 \mathrm{~K}^{46}$ for dry air), which is fairly constant with temperature. This gives a new version of the thermal balance equation:

$$
\left[\Delta T \times C_{p}^{g}\left(T_{e}\right) \times m_{g}\right]+\Delta P=\rho_{v}\left(T_{e}\right) \times \Delta H_{v a p}\left(T_{e}\right)
$$

where $m_{\mathrm{g}}$ is the mass of air (or gas) in gram per cubic meter. This can be obtained using the molar mass of air $\left(28.96 \mathrm{~g} \mathrm{~mol}^{-1}\right)$ where the absorbed water vapour is subtracted from the total number of moles of gas within the 
bubble per unit volume, using the ideal gas equation, at $T_{\mathrm{e}}$ and 1 atmosphere pressure. It should be noted that the mass of air or gas within a bubble remains constant as the bubble passes through the column. This equation appears to encompass a logical and reasonable thermophysical energy balance to describe the BCE process, especially at higher column solution temperatures, where the water vapour pressure will be more significant.

This model assumes that while bubbles are capturing water vapour and rising in the solution from their initial dry state to $100 \%$ water vapour saturation at $T_{e}$, they will expand further due to the water vapour captured into the bubbles but only the initial (and constant) mass of gas can supply heat to the column, to produce this level of evaporation.

In both balance equations $\Delta H_{\text {vap }}$ includes the work done by vapour expansion. However, for high gas temperatures and short bubble residence times, removing the water vapour expansion work produces a better fit when using Eq. (5) to give Eq. (6), which is adapted for no work of water vapour expansion and corresponds to the following equation:

$$
\left[\Delta T \times C_{p}^{g}\left(T_{e}\right) \times m_{g}\right]+\Delta P=\rho_{v}\left(T_{e}\right) \times\left[\Delta H_{v a p}\left(T_{e}\right)-P \Delta V\left(T_{e}\right)\right]
$$

Hence, it appears that high temperature bubbles in short height column solutions $(\sim 5 \mathrm{~cm})$ and short residence times appear to show no expansion due to vapour uptake (see Fig. 3). On the other hand, low temperature experiments appear to correspond to a steady state condition in terms of not only temperature but also the bubbles' vapour expansion. It is interesting that at low temperatures, Eq. (6) produces low errors for calculated $\Delta H_{\text {vap }}$ values, similar to those produced from Eq.(4) and Eq.(5), because the $P \Delta V$ term has no significant effect on the calculation. It should be noted that since bubbles reach vapour and temperature equilibrium within a few tenths of a second, the column height becomes important. In this work we define a medium height column to be one where this equilibrium is just attained.

It should be noted that use of $C_{p}^{g}$, the heat capacity of the dry air under constant volume conditions $(0.718$ $\mathrm{J} \mathrm{g}^{-1} \mathrm{~K}^{-1}$ for 270-330 $\mathrm{K}^{46}$ ) in place of the corresponding $C_{p}^{g}$ values gives inaccurate $\Delta H_{\text {vap }}$ values at both high and low column solution temperatures. This indicates that atmospheric work done on the contracting, cooling bubbles must be transferred to the column and so must be included in the energy balance equations.

Based on the results obtained and the analysis of energy balances in the BCE, the original balance Eq.(4) was found to be accurate for the determination of $\Delta H_{\text {vap }}$

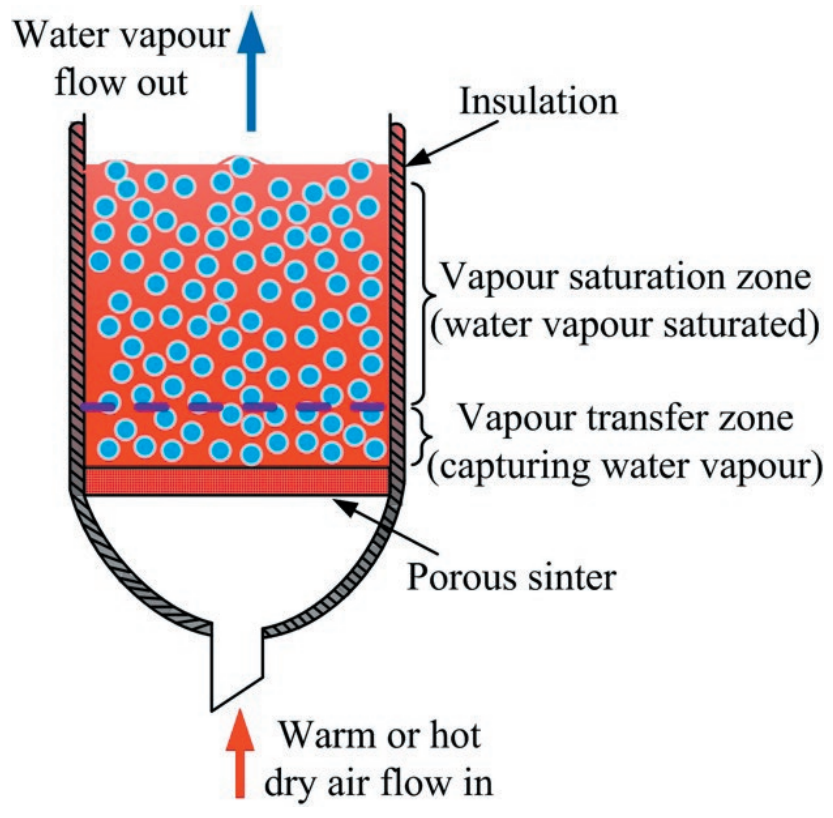

Figure 3. Schematic diagram of a bubble column (reprinted by permission of the publisher, Taylor\&Francis Ltd, http://www.tandfonline.com, from M. Shahid et al. 2015). ${ }^{8}$

values of salt solutions over a wide range of temperatures. In comparison, Eq.(5) can only be used at low temperatures and Eq. (6) is applicable to the special case of high inlet gas temperatures and short bubble residence times. Although the original Eq. (4) was derived for low temperatures, around room temperature, we have since shown that it also works well for very hot inlet gases. ${ }^{18}$ This is because any given bubble released into the column at high temperature $\left(T_{\mathrm{i}}\right)$ will contract until it reaches the column solution equilibrium temperature $T_{\mathrm{e}}$. The heat supplied by the bubble (of volume $\mathrm{V}_{\mathrm{b}}$ at temperature $T$ ) to the column, as it contracts, is given by the sum of $C_{\mathrm{p}}(T) \times V_{\mathrm{b}}(T)$ over the temperature range $T_{\mathrm{i}}$ to $T_{\mathrm{e}}$ (i.e. $\Delta T$ ). However, because the mass of gas in any given bubble remains constant, the value $C_{\mathrm{p}}(T) \times$ $V_{\mathrm{b}}(T)$ is also constant for any bubble and hence the heat transferred to the column is given by $C_{\mathrm{p}}\left(T_{\mathrm{e}}\right) \times \Delta T$, per unit volume, as given in Eq.(4).

The results obtained using inlet air temperatures at around $275{ }^{\circ} \mathrm{C}$ and for solutions ranging from 0.5-6 $\mathrm{m} \mathrm{NaCl}$ indicate that the amount of water carried over varied with different $\mathrm{NaCl}$ concentrations, relative to the expected vapour carry over, obtained from the variable theoretical column temperature (i.e. since the theoretical column temperature varies with increasing $\mathrm{NaCl}$ concentrations) and the corresponding vapour pressure. At the highest $\mathrm{NaCl}$ concentration, $6 \mathrm{~m}$, the calculated energy utilization at $275{ }^{\circ} \mathrm{C}$ was found to be about 29 
$\mathrm{MJ} \mathrm{m}^{-3}$ which indicates that the BCE process can be an energy effective method, especially at higher solution concentrations and hence could be used for industrial applications.

\section{APPLICATIONS OF THE BUBBLE COLUMN EVAPORATOR (BCE)}

The gas-liquid direct-contact bubble column evaporator is characterized by a continuously replenished, high gas-liquid interfacial area, which subsequently offers higher mass and heat transfer coefficients due to non-isothermal ${ }^{3}$ (i.e. localized evaporation) nature of the BCE. It could be applied in many large scale industrial applications. We now spell out in detail current applications of the bubble column evaporator (BCE) in aqueous systems:

4.1. Determination of $\Delta H_{\text {vap }}$ values for concentrated aqueous solutions using the BCE method

Bubble coalescence inhibition and rapid vapour transfer both offer a novel application of the BCE process for the precise measurement of $\Delta H_{\text {vap }}$ values for concentrated salt solutions ${ }^{3,6,15}$ where the vapour pressure values of salt solutions are known. $\Delta H_{\text {vap }}$ values can be obtained from the volumetric energy balance within the column, operating under steady state conditions, as defined by equation (4), at ambient temperatures. In recent work ${ }^{9,17}, \Delta H_{\text {vap }}$ values of various salt solutions at different concentrations have been obtained with accuracies, on average, within around $0.5-1.0 \%$ compared to the literature values for several salt solutions and demonstrate a measurement precision of between $0.1 \%$ and $0.9 \%$. For relatively low column temperature studies, around room temperature, the two balance equations, discussed earlier, give similar results, i.e. within the 0.5$1.0 \%$ range, on average.

The accuracy and precision of these $\Delta H_{\text {vap }}$ measurements was recently further improved using vacuum insulation (which reduced thermal transfers with the room environment) of the bubble column and an automatic data acquisition system for temperature readings. ${ }^{17}$ Under the steady state of the BCE system, hundreds of temperature data can be acquired by computer within 0.5-1 hour and hence a large number of $\Delta H_{\text {vap }}$ values can be produced using these energy balance equations. These $\Delta H_{\text {vap }}$ values $^{17}$ were found to pass the KolmogorovSmirnov test ${ }^{47}$ with high probabilities after standardization of data and supported the null hypothesis, that is, the normal distribution. Typical examples are shown in the frequency histograms given in Fig. $6 .{ }^{18}$ Narrow confidence intervals (95\%), say always around $\pm 0.02 \mathrm{~kJ} \mathrm{~mol}^{-1}$, also demonstrated the high precision of the BCE method for $\Delta H_{\text {vap }}$ measurement, as well as supporting the basic physics of the energy balance equation. At relatively higher operating or steady state temperatures, around 40 to $50^{\circ} \mathrm{C}$, the BCE method was still found to be suitable for determining $\Delta H_{\text {vap }}$ values of the salt solutions.

\subsection{BCE for evaporative cooling}

The steady state operating temperature of an aqueous solution in a bubble column can be calculated using the volumetric energy balance equation (4). The relation between inlet gas temperature and column top temperature using known $\Delta H_{\text {vap }}$ values and vapour pressure values for salt solutions or pure water, can be calculated for pure water and salt solutions. The steady state column solution temperature within the $\mathrm{BCE}$ is a function of the temperature of the inlet gas. ${ }^{9,10}$ This cooling effect has led to the suggestion that the BCE process could be used as a simple evaporative cooling system for buildings. This was earlier proposed by M.J. Francis and R.M. Pashley and published in 2009.10

When the BCE process is used with some types of salt solutions, which have coalescence inhibition effects on the bubbles, ${ }^{28}$ it will produce a high volume fraction of small bubbles which will enhance the water vapour transfer into the bubbles. The solution with dissolved salt $(\mathrm{NaCl})$ at $0.5 \mathrm{M}$ has a more efficient evaporative cooling effect and hence halves the time for the column to reach steady state conditions. As an example, inlet dry air at a temperature of $50{ }^{\circ} \mathrm{C}$ will cool the $0.5 \mathrm{~m} \mathrm{NaCl}$ column solution to less than $20^{\circ} \mathrm{C}$.

\subsection{Seawater desalination using the bubble column evapo- rator}

The dynamic BCE method has higher overall mass transfer and heat transfer coefficients, compared with the quiescent system. ${ }^{1}$ In this novel bubble column desalination system, water vapour can be captured and transported using a simple BCE system operated at temperatures well below the boiling point. The inhibition of bubble coalescence in salt solutions enables the design of a bubble column with a high volume fraction of small air bubbles, continuously colliding but not merging. This produces a uniform and efficient exchange of water vapour into the bubbles, which together with the high bubble rising velocity, due to its shape and trajectory based oscillations, allows water vapour to be rapidly 
absorbed into bubbles, condensed and then collected as pure water. ${ }^{17}$

The BCE method for seawater desalination, was examined and patented in 2013. ${ }^{48}$ The process is, of course, a reduced version of the natural phenomenon in which air is used as a carrier gas for desalting seawater through the rain cycle. However, the BCE process is based on the unexpected property of seawater in stopping air bubble coalescence ${ }^{11,28}$ because this facilitates a high packing volume of air bubbles, which are persistently colliding but are prevented from coalescing by the presence of salts. In addition, the bubbles produced in the 1-3 $\mathrm{mm}$ diameter range are ideally suited for rapid water vapour uptake. ${ }^{35}$ These factors form the basis of this enhanced process for the desalination of seawater. In addition, the BCE process offers an efficient vapour transfer mechanism in a continuous flow, with the evaporative bubble column operating below the boiling point. This method provides a very high surface area of air/water interface continuously produced and managed, naturally, by gas bubbling in salt water, such as seawater, to improve the efficiency of evaporation and transportation of the water saturated vapour producing drinking water from seawater. ${ }^{36}$

In the first reported experiments, ${ }^{17}$ seawater was first heated to $70{ }^{\circ} \mathrm{C}$ then air bubbles ranging from $1-3 \mathrm{~mm}$ diameter were produced via a glass sinter (porosity No.2) and was passed continuously through heated seawater. After bubbling for $60 \mathrm{~min}$, the temperature of the solution in the column had fallen to about $52^{\circ} \mathrm{C}$. The starting and finishing temperatures were used to estimate the theoretical yield expected for complete collection and condensation of the water vapour, at the average temperature of the column. The electrical conductivity of the bubble column solution was reduced from $49 \mathrm{mS} \mathrm{cm}^{-1}$ (seawater) to $6 \mu \mathrm{S} \mathrm{cm}^{-1}$ (well below the levels required for acceptable drinking water). ${ }^{17}$ One of the advantages is that renewable sources of energy (i.e. solar energy system) could easily be coupled with a bubble column system. ${ }^{17}$

\subsection{Enhanced supersaturated bubble column desalination}

In these experiments hot, dry, air bubbles ranging from 150 to $275^{\circ} \mathrm{C}$ at about $23 \mathrm{~L} \mathrm{~min}^{-1}$ were first passed through an empty dry BCE column and then a known mass of the solution was quickly added. However, in these experiments $200 \mathrm{~g}$ of $0.5 \mathrm{~m} \mathrm{NaCl}$ was added with and without $0.002 \mathrm{~g}$ of a non-ionic surfactant $\left(\mathrm{C}_{12} \mathrm{EO}_{8}\right)$. The temperature of the solution was then measured every minute throughout the $30 \mathrm{~min}$ bubbling runs. After 30 min, the column and remaining solution was detached and weighed. Since the dry weight of the column was also known, the total amount of water vapour removed in each experiment was easily measured. ${ }^{17}$ The results obtained show that increasing the temperature of the inlet air increases the water vapour carryover expected from the column solution vapour pressure and the air volume passed. The results obtained also showed that with added surfactant the carryover increased even more.

It seems likely that the use of the non-ionic surfactant, octaethylene glycol monododecyl ether $\left(\mathrm{C}_{12} \mathrm{EO}_{8}\right)$, provides a monolayer coating at the surface of bubbles.

Thus, it appears that the packed mono-layer of surfactant molecules allows water vapour transport into the bubbles but inhibits this vapour from re-condensing on the interior, now hydrophobic, walls of the bubbles. Hence, the surfactant layer acts like a "Surface molecular diode", which facilitates water vapour transport in one direction. This supersaturation of the air bubbles then produces increased water vapour carryover. ${ }^{17}$

\subsection{Enhanced bubble column desalination using helium as a carrier gas}

Helium as inlet gas can increase the BCE performance more than 3.3 times higher compared with expected equilibrium vapour pressure, which is significant. It suggests that $\mathrm{He}$ as a carrier gas could be a promising solution for efficient seawater desalination.

It was suggested previously ${ }^{48,49}$ that a suitable clathrate-forming carrier gas might be used to vaporize water not as individual molecules but in clusters and so remove the high thermal energy required for vapour phase desalination. A clathrate-forming gas partially dissolved in the aqueous solution would equilibrate with the gas in the bubbles and produce water clusters in the highly turbulent water. So providing conditions that favour enhanced evaporation with lower temperatures. ${ }^{48}$ Helium produces different lattice structures to capture water molecules in gas form with multiple cages over a wide range of pressure and temperature. This was found by employing optimising dynamic method to determine free Gibbs energy of the He clathrate hydrates produced. Results showed that among different He clathrate hydrates, sI hydrate and filled ice II are relatively metastable comparing to sII hydrate form. ${ }^{50}$

Another possible explanation for the high performance of helium in the BCE desalination is based on the simple idea that the continuous flow of heated He sparge gas breaks down a small proportion of the hydrogen bonding network within water molecules due to its small size. This would also reduce the $\Delta H_{\text {vap }}$ value. For example, a decrease in hydrogen bonding of 3.6 to 3.2, due to 
a modest increase in temperature, of 0 to $70{ }^{\circ} \mathrm{C}$, corresponds to a decrease in $\Delta H_{\text {vap }}$ of about $3 \mathrm{~kJ} / \mathrm{mol} .^{19}$ The effect of this reduction can be roughly estimated using fundamental thermodynamics.

That is from the standard equations of equilibrium:

$\Delta G=\Delta H-T \Delta S$ and

$\Delta G^{0}=-R T \ln K_{e q} \leftrightarrow K_{e q}=\exp \left(-\frac{\Delta G^{0}}{R T}\right)$

It can be assumed that the entropy difference of conversion water to gas (liquid $\leftrightarrow$ gas) will be constant for either air or He. So, any difference in vaporization entropy change for the two gases will be insignificant, that is: $\mathrm{d}(\Delta S)=0$ and Eq. (8) becomes:

$d(\Delta G)=d\left(\Delta H_{v a p}\right)$

Given this and the water density ratio of $\mathrm{He}$ comparing to air $\left(K_{e q}=\frac{\rho_{H e}^{W}}{\rho_{\text {air }}^{w}}=3.3\right)$, Eq. (9) becomes:

$K_{e q}=\frac{\rho_{H e}^{W}}{\rho_{\text {air }}^{W}}=3.3=\exp \left(-\frac{d\left(\Delta H_{v}\right)}{R T}\right)$

In this equation, $\mathrm{R}$ is the gas constant and $\mathrm{T}$ is the average column temperature, and average $d\left(\Delta H_{\text {vap }}\right)$ is calculated to be $-3 \mathrm{~kJ} \mathrm{~mol}^{-1}$. The expected $\Delta H_{\text {vap }}$ values for different column temperatures is, on average, about $43.4 \mathrm{~kJ} \mathrm{~mol}^{-1}$, so with He experiments, a $7 \%$ reduction of $\Delta H_{\text {vap }}$ is sufficient to explain the enhanced water vapour carryover. ${ }^{19}$

\subsection{Comparison and benefits}

The main advantages of the BCE desalination system are its simplicity, resilience to feed water purity and the fact that it is a continuous and controlled, nonboiling process. These are clear advantages over the two most common seawater desalination processes currently used, that is seawater reverse osmosis (SWRO) and thermal desalination (such as MSF). There is little room left for improvement in SWRO but thermal desalination methods can still be substantially improved. Methods such as the BCE which represent low capital investment do not rely on rare materials or complex manufacturing and ready use of waste heat and sustainable energy sources, such as wind power, offer fewer constraints than the other common processes.

The main advantages in the BCE system for water desalination are listed below.

- The BCE collects water vapour throughout the entire body of the salt solution as compared to MSF, which uses only the surface of the heating plates as the main water vapour transfer site.
- $\quad$ The BCE process is uniform and controlled because it does not involve boiling.

- Very fast vapour collection of a few tenths of a second for 1-3 mm diameter bubbles.

- High rising velocity of saturated bubbles within the BCE system.

- Air flow produces continuously renewed bubbles and high surface area of evaporating surfaces.

- No requirement for feedwater pre-treatment as in SWRO.

- System is self-cleaning via the flotation process.

- Sub-boiling process easier to control compared with MSF and doesn't produce scaling.

- Can concentrate to a much higher level, up to $6 \mathrm{~m}$ $\mathrm{NaCl}$, than either SWRO or MSF, i.e. produces higher recovery rate.

- Simple design will give low capital cost compared with MSF.

- $\quad$ Single stage and continuous process produces high quality water.

- Well suited for sustainable wind power for air flow generation and use of waste industrial hot gases.

- Does not need vacuum pumps to reduce pressure and boiling point, compared with MSF.

- Use of heated gas inflow offers an ideal process for control of column temperature and hence evaporation rate.

\subsection{Water sterilization using the BCE}

The high heat transfer coefficients created within the BCE system can be used to thermally destroy biological organisms well below the boiling point and it has recently been established that sterilization occurs due to transitory impact of biological species with hot gas bubbles by collisions with the heated air-water interface, although the column temperature remains low and actually even favours the growth of bacterial colonies present in typical contaminated water. ${ }^{21-22}$

In the first BCE sterilization study, ${ }^{22}$ hot gas bubbles up to $150{ }^{\circ} \mathrm{C}$ were used and in a more recent study bubbles up to $250{ }^{\circ} \mathrm{C}^{21}$ were passed into a water column via a glass sinter with $40-100 \mu \mathrm{m}$ pores. The effects of exposure on sterilizing water were examined with different time intervals and typical results showed that only 2 min flow of $250{ }^{\circ} \mathrm{C}$ air was required to destroy almost all of the coliforms in the solution. The degree of sterilization was determined using natural lake water heavily contaminated with coliforms from waterfowl and land run-off. These coliform counts, obtained through the membrane filtration method, were used to measure the degree of sterilization using hot gas bubbling under 
a range of conditions but in all cases where the column solution temperature never exceeded the optimum growing temperature for the coliforms. ${ }^{21-22}$

The presence of a salt that inhibits bubble coalescence in the solution serves to preserve finer bubbles of the heated gas, enhancing the number of bubble collisions with the biological species by ensuring a higher gas-liquid contact surface area and higher surface area per gas volume which leads to improved sterilization rates.

The use of added $\mathrm{NaCl}$ enhances the rate of water sterilization as air bubbles more typically in the approximate size range of 1 to $3 \mathrm{~mm}$ diameter increase the probabilities of bubble collisions with typically small microorganisms ranging from 2 to $5 \mu \mathrm{m}$ in size. It is worth mentioning that after 2 mins very few coliform colonies were still observed for columns with added $\mathrm{NaCl}$ in the solution, which produced the smaller bubbles.

\subsection{Thermolysis of solutes in aqueous solution}

Thermal sterilization studies with the BCE led to the suggestion that this process could also facilitate thermal decomposition of some solutes in aqueous solutions, even at lower solution temperatures and at a faster rate than is normally produced via the direct heating of a bulk solution. Studies of the use of the BCE process for the thermal decomposition of solutes have recently been reported. ${ }^{8,52}$ This study examined the thermal decomposition of ammonium bicarbonate $\left(\mathrm{NH}_{4} \mathrm{HCO}_{3}\right)$ in aqueous solution. This salt has been used for important applications, such as a draw solution in Forward Osmosis ${ }^{53}$ and, more recently, in the regeneration of ion exchange resins. ${ }^{54} \mathrm{~A}$ second solute in widespread use is potassium persulfate $\left(\mathrm{K}_{2} \mathrm{~S}_{2} \mathrm{O}_{8}\right)$ which was also studied in aqueous solutions. This salt is often used as a radical initiator for the process of emulsion polymerization. ${ }^{55}$

\subsubsection{Decomposition of $\mathrm{NH}_{4} \mathrm{HCO}_{3}$ solutions}

Typical decomposition results obtained using different solution conditions ${ }^{8}$ clearly demonstrate that the $\mathrm{BCE}$ process is much more efficient for $\mathrm{NH}_{4} \mathrm{HCO}_{3}$ decomposition, especially compared with the standard method, which is, using a stirred water bath at the same solution temperature, of $45^{\circ} \mathrm{C}$. For example, in the BCE process, $90 \%$ thermal decomposition of $\mathrm{NH}_{4} \mathrm{HCO}_{3}$ was obtained after $30 \mathrm{~min}$ of bubbling of $150{ }^{\circ} \mathrm{C}$ air through $0.5 \mathrm{~m}$ solutions. ${ }^{8}$

The initial high $(2 \mathrm{~m})$ concentration of $\mathrm{NH}_{4} \mathrm{HCO}_{3}$ used in these BCE experiments was found to inhibit bubble coalescence, producing small bubbles. However, after $30 \mathrm{~min}$ of the $\mathrm{BCE}$ process, the significant reduction in $\mathrm{NH}_{4} \mathrm{HCO}_{3}$ concentration produced larger bubbles of the same diameter as those observed in pure water, which also confirms the decomposition of $\mathrm{NH}_{4} \mathrm{HCO}_{3}$ salt into ammonia and carbon dioxide gases. ${ }^{8}$

\subsubsection{Proposed Mechanism of BCE Solute}

Pre-heated gas bubbles introduced and passed through the aqueous solution, must produce a transient hot surface layer around each rising bubble. The transient hot surface layer will have a higher temperature than the average temperature of the aqueous solution. We believe that it is the interaction of the solute with this transient hot surface layer which results in the thermal decomposition of the solute, even when the average temperature of the aqueous solution remains below the temperature at which it would normally cause thermal/ chemical decomposition of the solute. For situations where thermal decomposition is either required very quickly or at reduced temperature, the BCE method offers a new approach.

\subsection{Inhibition of particle growth in a $B C E$}

At first, it might appear that the BCE process, with continuous water evaporation via the rising dry bubbles, could be used to slowly increase supersaturation levels and hence cause precipitation. However, it was discovered ${ }^{23}$ using aqueous $\mathrm{CaCl}_{2}$ and $\mathrm{K}_{2} \mathrm{SO}_{4}$ mixtures that the $\mathrm{BCE}$ process actually has a significant inhibition effect on the precipitation process, and as these particles grow the turbidity was monitored with time during the precipitation. In this case, with no added foreign nucleating particles, turbidity values within the BCE solutions were fairly constant with time over more than 300 mins, even though in quiescent solutions, at this same supersaturation level, significant particle growth was observed much earlier.

These results suggest that the high density of rising bubbles might disrupt sub-nuclei or molecular clusters in the solution during precipitation and, in addition, the charged surfaces of the bubbles might have a big perturbation on interacting ions involved in nucleation and growth. A similar phenomenon was reported by J. W. Mullin and K. D. Raven ${ }^{56-57}$ who found that an increase in the intensity of agitation does not always lead to an increase in nucleation, which might be explained by assuming that agitation can disrupt sub-nuclei or molecular clusters in the solution. Stirred systems are also 
complex in that, for example, different types of impellers can have a significant effect on other process parameters of crystallization ${ }^{58}$ and can lead to the production of different crystal shapes. ${ }^{59}$

\subsection{Other potential applications}

The BCE process, in addition to its applications in wastewater concentration, could at the same time be used to inactivate different types of viruses and enzymes in the wastewater. The BCE hot air system could also possibly be used for the sterilization of dairy and dairy based products and could even be used for the production of chiral compounds. In addition, the bubble column system could be effective in treating water-based foods, beverages, blood and blood related products and it might also be employed in specific stages for the treatment of pharmaceutical products. The BCE could also be used for carbon capture by adding surfactant to produce a continuous flow of $\mathrm{CO}_{2}$ foam from hot waste industrial gases. This foam could be transported and then buried under pressure to reduce total volume and foam cell size for long term storage.

\section{CONCLUSIONS}

This updated review article examines the theoretical background and the applicability of the BCE process to several important industrial applications. The design and development of the BCE are established on the two main features (1) higher overall mass transfer coefficient and (2) efficient heat transfer coefficient, which is a prerequisite for different bubble column evaporator applications. It is argued that a thorough and in-depth understanding of the BCE system, when used with aqueous solutions, is critically dependent on the physical properties of water. Further detailed studies would be required to develop large scale industrial applications of this technique.

\section{ACKNOWLEDGEMENT}

The authors would like to thank the Australian Research Council for funding this project.

\section{LIST OF PARAMETERS, DEFINITIONS AND UNITS}

$\left(\Delta H_{\text {vap }}\right)$ : enthalpy of vaporization $(\mathrm{kJ} / \mathrm{mol})$

CMC: critical micelle concentration of a surfactant (M) $t_{\mathrm{bl}}$ : bubble layer thickness $(\mathrm{m})$
$\rho_{\mathrm{w}}^{v}\left(T_{c}\right)$ : is the water vapour density at the steady state column temperature $\left(T_{c}\right)$ (in $\mathrm{mol} / \mathrm{m}^{3}$ )

r: radius of the bubble $(\mathrm{m})$

$\rho_{w}$ : is the liquid water density $\left(\mathrm{mol} / \mathrm{m}^{3}\right)$

$C_{\mathrm{p}}$ and $C_{\mathrm{s}}$ : are the air (at constant pressure) and solution (or water) specific heat capacities (in $\mathrm{J} / \mathrm{m}^{3} \mathrm{~K}$ )

$\Delta t$ : estimated transient temperature increase in the solution layer surrounding the bubbles $(\mathrm{K})$

$\Delta T$ : temperature reduction within the cooling bubbles $(\mathrm{K})$

$\delta$ : estimated heated layer thickness around partially cooled hot bubble (m)

$T_{i}$ : initial bubble temperature $(\mathrm{K})$

$T_{b}$ : temperature of partially cooled bubbles (in $\mathrm{K}$ ) assumed to be equal to $100{ }^{\circ} \mathrm{C}$

$T_{c}$ : column solution temperature $(\mathrm{K})$

$U_{\infty}$ : is the bubble rise velocity in an infinite liquid $(\mathrm{m} / \mathrm{s})$

$\eta$ : is the coefficient of viscosity of the liquid $\left(\mathrm{Nsm}^{-2}\right)$

$\rho_{w}$ : is the density of the liquid $\left(\mathrm{kg} / \mathrm{m}^{3}\right)$

$a$ : is the gas bubble radius in eqn (3) (m)

$g:$ is the gravitational constant $\left(9.81 \mathrm{~m} / \mathrm{s}^{2}\right)$

$k$ : in eqn (3) is a bubble rise constant

$C_{p}\left(T_{\mathrm{e}}\right)$; is the specific heat per unit volume of gas at constant pressure and at temperature $T_{\mathrm{e}}\left(\mathrm{J} / \mathrm{m}^{3} \mathrm{~K}\right)$

$T_{e}$ : steady state temperature of the solution in a bubble column (K)

$\rho_{v}\left(T_{e}\right)$ : is the water vapour density at temperature $\mathrm{T}_{\mathrm{e}}$ $\left(\mathrm{mol} / \mathrm{m}^{3}\right)$

$\Delta H_{\text {vap }}\left(T_{e}\right)$ : is the enthalpy of vaporization of water at temperature $\mathrm{T}_{\mathrm{e}}(\mathrm{J} / \mathrm{mol})$

$\Delta T$ : is the temperature difference between the gas entering and leaving the column $(\mathrm{K})$

$\Delta P:$ is the hydrostatic differential pressure, between the gas inlet into the sinter and atmospheric pressure at the top of the column $(\mathrm{Pa})$

$C_{p}^{g}\left(T_{\mathrm{e}}\right)$ : mass heat capacity of gas at temperature $\mathrm{T}_{\mathrm{e}}(\mathrm{J} / \mathrm{kg}$ $\mathrm{K})$

$m_{\mathrm{g}}$ : is the mass of air (or gas) per cubic meter at $\mathrm{T}_{\mathrm{e}}(\mathrm{kg} /$ $\mathrm{m}^{3}$ )

$P$ : gas pressure $(\mathrm{Pa})$

$\Delta V$ : change in gas volume at temperature $\mathrm{T}_{\mathrm{e}}\left(\mathrm{m}^{3}\right)$

$C_{v}^{g}$ : the heat capacity of gas under constant volume conditions $\left(\mathrm{J} / \mathrm{m}^{3} \mathrm{~K}\right)$

$C_{p}^{g}$ : the heat capacity of gas under constant pressure conditions $\left(\mathrm{J} / \mathrm{m}^{3} \mathrm{~K}\right)$

$V_{b}$ : volume of a bubble $\left(\mathrm{m}^{3}\right)$

$r^{w}{ }_{H e}$ : water vapour density from helium sparged solution $\left(\mathrm{mol} / \mathrm{m}^{3}\right)$

$r^{w}{ }_{a i r}$ : water vapour density from air sparged solution $\left(\mathrm{mol} / \mathrm{m}^{3}\right)$

$R$ : gas constant $(\mathrm{J} / \mathrm{K} \mathrm{mol})$ 


\section{REFERENCES}

1. P. Zehner, M. Kraume, Bubble columns, Ullmann's Encyclopedia of Industrial Chemistry, 2000.

2. A. H. Luedicke, B. Hendrickson, G. M. Pigott, A method for the concentration of proteinaceous solutions by submerged combustion, J. Food Sci., 1979, 44, 1469-1473.

3. C. P. Ribeiro, P. L. C. Lage, Gas-Liquid Direct-Contact Evaporation: A Review, Chem. Eng. Technol., 2005, 28 (10), 1081-1107.

4. M. Schluter, A-M. Billet, S. Herres-Pawlis, Reactive Bubbly Flows, Chem. Eng. Technol., 2017, 40 (8), 1384.

5. J. B. Joshi, K. Nandakumar, G. M. Evans, V. K. Pareek, M. M. Gumulya, M. J. Sathe, M. A. Khanwale, Bubble generated turbulence and direct numerical simulations, Chem. Eng. Sci., 2017, 157, 26-75.

6. Y. T. Shah, B. G. Kelkar, S. P. Godbole, W. D. Deckwer, Design parameters estimations for bubble column reactors, AIChE Journal, 1982, 28 (3), 353-379.

7. V. I. Klassen, V. A. Mokrousov, An introduction to the theory of flotation, London: Butterworths, 1963.

8. M. Shahid, X. Xue, C. Fan, R.M. Pashley, Study of a novel method for the thermolysis of solutes in aqueous solution using a low temperature bubble column evaporator, J. Phys. Chem. B, 2015, 119 (25), 80728079.

9. C. Fan, M. Shahid, and R. M. Pashley, Studies on bubble column evaporation in various salt solutions, J. Sol. Chem., 2014, 43 (8), 1297-1312.

10. M. J. Francis, R. M. Pashley, Application of a Bubble Column for Evaporative Cooling and a Simple Procedure for Determining the Latent Heat of Vaporization of Aqueous Salt Solutions, J. Phys. Chem. B, 2009, 113 (27). 9311-9315.

11. V. S. J. Craig, B. W. Ninham, R. M. Pashley, The effect of electrolytes on bubble coalescence in water, J. Phys. Chem., 1993, vol. 97(39), 10192-10197.

12. Hierarchies of forces: The last 150 years, Advances in Colloid \& Interface Science, 1982, 16 (1), 3-15.

13. Proceedings of the IUTAM-IUPAC Symposium on Interaction of Particles in Colloidal Dispersions, Canberra, March 1981.

14. V. S. J. Craig, Bubble coalescence and specific-ion effects, Curr. Opin. Colloid Interface Sci., 2004, 9 (1), 178-184.

15. S. Marcelja, Short-range forces in surface and bubble interaction, Curr. Opin. Colloid Interface Sci., 2004, 9 (1), 165-167.

16. B. P. Reines, B. W. Ninham, Structure and Function of the Endothelial Surface Layer: unravelling the nano-architecture of biological surfaces. Quarterly Reviews of Biophysics, 2019, 52, 1-11.

17. M. J. Francis, R. M. Pashley, Thermal desalination using a non-boiling bubble column, Desalin. Water Treat., 2009, 12 (1-3), 155-161; M. Shahid, R. M. Pashley, A study of the bubble column evaporator method for thermal desalination, Desalination, 2014, 351, 236-242.

18. C. Fan, R.M. Pashley, Precise Method for Determining the Enthalpy of Vaporization of Concentrated Salt Solutions Using a Bubble Column Evaporator, J. Sol. Chem., 2015, 44 (1), 131-145.

19. M. Taseidifar, M. Shahid, R. M. Pashley, A study of the bubble column evaporator method for improved thermal desalination, Desalination, 2018, 432, 97-103.

20. X. Xue, R. M. Pashley, A study of low temperature inactivation of fecal coliforms in electrolyte solutions using hot air bubbles, Desalin. Water Treat., 2015, 1-11.

21. M. Shahid, A study of the bubble column evaporator method for improved sterilization, J. Water Process. Eng., 2015, 8, 1-6.

22. M. Shahid, R. M. Pashley, M. Rahman, Use of a high density, low temperature, bubble column for thermally efficient water sterilization, Desalin. Water Treat., 2014, 52, 4444-4452.

23. C. Fan, R. M. Pashley, The controlled growth of calcium sulfate dihydrate (gypsum) in aqueous solution using the inhibition effect of a bubble column evaporator, Chem. Eng. Sci., 2016, 142, 23-31.

24. P. N. Govindan, G. P. Thiel, R. K. McGovern, J. H. Lienhard, M. H. Elsharqawy, Bubble-Column Vapor Mixture Condenser, US8523985, Google Patents.

25. G. P. Narayan, J. H. Lienhard, Thermal Design of Humidification-Dehumidification Systems for Affordable Small-Scale Desalination, IDA J. Desalin. Water Reuse, 2012, 4 (3), 24-34.

26. M. Schmack, H. Goen, and A. Martin, A Bubble Column Evaporator with Basic Flat-plate Condenser for Brackish and Seawater Desalination, Environ. Technol., 2015, 37 (1), 74-85.

27. P. Ghosh, Coalescence of air bubbles at air-water interface, Chem. Eng. Res. Des., 2004, 82 (7), 849-854.

28. V. S. J. Craig, B. W. Ninham, R. M. Pashley, Effect of electrolytes on bubble coalescence, Nature, 1993, 364 (6435), 317-319.

29. B. W. Ninham, R. M. Pashley, P. Lo Nostro, Surface forces: Changing concepts and complexity with dissolved gas, bubbles, salt and heat, Current Opinion in Colloid \& Interface Science, 2016, 27, 25-32.

30. M. Alheshibri, J. Qian, M. Jehannin and V. S. J. Craig, A history of nanobubbles. Langmuir, 2016, 32(43), 11086-11100. 
31. E. C. W. Clarke, D. N. Glew, Evaluation of the thermodynamic functions for aqueous sodium chloride from equilibrium and calorimetric measurements below $154{ }^{\circ} \mathrm{C}$, J. Phys. Chem. Ref. Data, 1985, 14, 489, 1985.

32. D. E. Garrett, Handbook of lithium and natural calcium chloride, London: Academic Press, 2004.

33. D. R. Lide, T. J. Bruno, CRC handbook of chemistry and physics: CRC Press, Boca Raton, 2012.

34. A. G. Sanchis, R. M. Pashley, B. W. Ninham, Virus and bacteria inactivation by $\mathrm{CO}_{2}$ bubbles in solution, NPJ Clean Water, 2019, 2.

35. I. Leifer, R. K. Patro, P. Bowyer, A study on the temperature variation of rise velocity for large clean bubbles, J. Atmos. Ocean. Tech., 2000, 17(10), 1392-1402.

36. R. M. Pashley, M. J. Francis, M. Rzechowicz, Unusual properties of water: Effects on desalination processes, Water, 2008, 35 (8), 67-71.

37. A. A. Kulkarni, J. B. Joshi, Bubble formation and bubble rise velocity in gas-liquid systems: A review, Industrial \& Engineering Chemistry Research, 2005, 44(16), 5873-5931.

38. R. Clift, J. Grace, M. Weber, Bubbles, drops and particles New York, Academic Press, 1978.

39. J. J. Quinn, M. Maldonado, C. O. Gomez, J. A. Finch, Experimental study on the shape-velocity relationship of an ellipsoidal bubble in inorganic salt solutions, Minerals Engineering, 2014, 55, 5-10.

40. P. Gonzaleztello, F. Camacho, E. Jurado, M. P. Paez, Influence of surfactant concentration on the final rising rate of droplets, Canadian J. Chem. Eng., 1992, 70(3), 426-430.

41. X. Luo, J. Zhang, K. Tsuchiya, L. S. Fan, On the rise velocity of bubbles in liquid-solid suspensions at elevated pressure and temperature, Chem. Eng. Sci., 1997, 52(21), 3693-3699.

42. K. W. K. Li, and A. Schneider, Rise velocities of large bubbles in viscous Newtonian liquids, J. American Ceramic Soc., 1993, 76(1), 241-244.

43. V. G. Levich, S. Technica, Physicochemical hydrodynamics: Prentice-hall Englewood Cliffs, NJ, 1962.

44. D. Y. Chan, E. Klaseboer, R. Manica, Film drainage and coalescence between deformable drops and bubbles, Soft Matter, 2011, 7(6), 2235-2264.

45. E. Klaseboer, R. Manica, D. Y. Chan, B. C. Khoo, BEM simulations of potential flow with viscous effects as applied to a rising bubble, Eng. Anal. Bound. Elem., 2011, 35(3), 489-494.

46. E. W. Lemmon, R. T. Jacobsen, S. G. Penoncello, D. G. Friend, Thermodynamic properties of air and mixtures of nitrogen, argon, and oxygen from 60 to $2000 \mathrm{~K}$ at pressures to $2000 \mathrm{MPa}$, J. Phys. Chem. Ref.
Data, 2000, 29(3), 331.

47. F. J. Massey Jr, The Kolmogorov-Smirnov test for goodness of fit, J. Amer. Statist. Assoc., 1951, 46(253), pp. 68-78.

48. R. M. Pashley, Method for desalination, US20090120877; Google Patents.

49. E. W. Hough, M. J. Rzasa, B. B. Wood, Interfacial Tensions at Reservoir Pressures and Temperatures; Apparatus and the Water-Methane System, Journal of Petroleum Technology, 1951, 192, 57-60.

50. R. V. Belosludov, Y. Y. Bozhko, O. S. Subbotin, V. R. Belosludov, H. Mizuseki, Y. Kawazoe, V. M. Fomin, Stability and Composition of Helium Hydrates Based on Ices Ih and II at Low Temperatures, J. Phys. Chem. C, 2014, 118(5), 2587-2593.

51. C. Fan, A Study of Some Physical Properties of Concentrated Salt Solutions Using the Bubble Column Evaporator, PhD Thesis. School of Physical, Environmental and Mathematical Sciences, The University of New South Wales, 2016.

52. R. M. Pashley, X. Xue, C. Fan, M. Shahid, Method for assisting thermally-induced changes, AU2015901956, 2015.

53. J. R. McCutcheon, R. L. McGinnis, M. Elimelech, A novel ammonia-carbon dioxide forward (direct) osmosis desalination process, Desalination, 2005, 174(1), 1-11.

54. N. P. G. N. Chandrasekara, and R. M. Pashley, Study of a new process for the efficient regeneration of ion exchange resins, Desalination, 2015, 357, 131-139.

55. M. Okubo, T. Mori, The decomposition of potassium persulphate used as initiator in emulsion polymerization, Makromolekulare Chemie. Macromolecular Symposia, 1, Wiley Online Library, 1990, 143-156.

56. J. W. Mullin, K. D. Raven, Influence of mechanical agitation on the nucleation of some aqueous salt solutions, Nature, 1962, 195, 35-38.

57. J. W. Mullin, K. D. Raven, Nucleation in Agitated Solutions, Nature, 1961, 190(4772), 251.

58. W. Beckmann, Crystallization: Basic Concepts and Industrial Applications, Weinheim: John Wiley \& Sons, 2013.

59. I. Mukhopadhyay, V. P. Mohandas, G. R. Desale, A. Chaudhary, P. K. Ghosh, Crystallization of Spherical Common Salt in the Submillimeter Size Range without Habit Modifier, Ind. Eng. Chem. Res., 2010, 49(23), 12197-12203. 